\title{
Orações concessivas prefaciadas por a pesar de e a pesar de que no espanhol peninsular falado: factualidade, pressuposição e tempo de referência à luz do funcionalismo
}

\author{
Talita Storti Garcia* \\ Bárbara Ribeiro Fante**
}

\begin{abstract}
RESUMO
Este trabalho visa a descrever, tendo como base a teoria da Gramática Discursivo-Funcional, as orações concessivas prefaciadas por a pesar de (que) no espanhol peninsular falado, com o objetivo de verificar em que medida os critérios Factualidade, Pressuposição e Tempo de Referência podem distinguir a pesar de e a pesar de que e como esses fatores podem ser reconhecidos na materialidade linguística dessas construções, uma vez que a pesar de e a pesar de que introduzem estruturas de naturezas diferentes, sendo, respectivamente, frases nominais e orações. O universo de investigação consiste no corpus do projeto PRESEEA(Proyecto para el Estudio Sociolinguístico del Español de España y de América) e no corpus do projeto CREA (Corpus de Referencia del Español Actual). Os resultados mostram que as orações prefaciadas por $a$ pesar de tendem a veicular uma informação factual e pressuposta enquanto a pesar de que tende a apresentar uma informação também factual, mas que pode ser pressuposta ou não-pressuposta. A análise revela que o fator determinante para diferenciar essas duas conjunções é o Tempo de Referência, pois a pesar de apresenta Tempo de Referência Dependente, enquanto a pesar de que, Tempo de Referência Independente.
\end{abstract}

Palavra-chave: Gramática Discursivo-Funcional. Concessão. Espanhol falado. A pesar de. A pesar de que.

* Professora do Departamento de Letras Modernas - IBILCE - UNESP.

** Aluna do Mestrado do Programa de Pós-Graduação em Estudos Linguísticos da UNESP de São José do Rio Preto, onde cursou Licenciatura em Letras - habilitação Português/Espanhol. Atualmente,

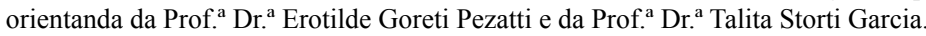




\section{Considerações iniciais}

Este trabalho apresenta as principais considerações a respeito da conjunção concessiva do espanhol a pesar de (que), com o objetivo de verificar como a pesar de e a pesar de que se diferenciam, tendo como parâmetros de análise a Factualidade, a Pressuposição e o Tempo de Referência das estruturas envolvidas ${ }^{1}$. Pesquisa anterior (cf. GARCIA; FANTE, 2015) mostra que as estruturas introduzidas por a pesar de atuam no Nível Representacional, na camada do Estado-de-Coisas, e que as estruturas prefaciadas por a pesar de que operam no Nível Interpessoal, nas camadas do Ato Discursivo e do Movimento, ou seja, atuam em distintas camadas do modelo teórico adotado, a Gramática Discursivo-Funcional, o que nos impulsiona a investigar quais outros fatores, além dos já estudados em Garcia e Fante (2015), diferenciam esses dois nexos.

Este estudo pretende responder às seguintes questões: (i) Em que medida os critérios Factualidade, Pressuposição e Tempo de Referência podem ajudar na distinção entre a pesar de e a pesar de que? (ii) Como esses critérios podem ser reconhecidos na materialidade linguística dessas construções?

Utilizam-se como universo de investigação amostras do espanhol falado das cidades de Alcalá de Henares, Granada, Valencia e Madri pertencentes ao Projeto PRESEEA - Proyecto para el Estudio Sociolingüistico del Español de España y de América, e também amostras do espanhol falado do córpus CREA (Corpus de Referencia del Español Actual).

Apresentaremos, inicialmente, neste trabalho, na seção (1), os pressupostos teóricos da Gramática Discursivo-Funcional e também um resumo dos resultados obtidos na primeira fase da investigação (cf. GARCIA; FANTE, 2015) com a conjunção a pesar de (que) necessários para compreender a análise deste artigo. Na seção (2), por sua vez, apresentaremos os conceitos básicos dos critérios Factualidade nas orações concessivas (2.1), Pressuposição (2.2) e Tempo de Referência (2.3). Já na seção (3) apresentaremos os resultados encontrados com base em nossas análises e, finalmente, faremos as Considerações Finais a respeito desta investigação.

1 Agradecemos à FAPESP (Fundação de Amparo à Pesquisa do Estado de São Paulo) - Processo 2013/20839-5 - pelo apoio concedido para a realização deste trabalho, que integra um projeto maior que investiga todas as relações concessivas no espanhol, desenvolvido junto ao Departamento de Letras Modernas da UNESP, Campus de São José do Rio Preto, pela Prof. ${ }^{a}$ Dr. ${ }^{a}$ Talita Storti Garcia. 


\section{Pressupostos teóricos e considerações a respeito de a pesar de (que) à luz da Gramática Discursivo-Funcional}

A Gramática de la Real Academia Española (1991) e a Nueva Gramática de la Real Academia Española (2009) - (doravante NGRAE) - definem a concessão como um grupo oracional que demonstra uma objeção real ou possível ao que está sendo dito na oração principal, asseverando que essa objeção não anula o que foi afirmado na oração principal, como demonstra (1):

A pesar de la lluvia, voy. ${ }^{2}$ (Real Academia Española 1991, p. 397 - adaptado)

Em (1), nota-se que a chuva poderia, mas não impede a realização da situação denotada na oração principal, no fato de ir (voy), o que caracteriza uma relação concessiva.

Já na visão da Gramática Discursivo-Funcional (doravante GDF), a concessão é uma função retórica utilizada pelo falante quando ele acha que o seu ouvinte não esperava o Conteúdo Comunicado apresentado na oração anterior (KEIZER, 2015).

A GDF é uma teoria que deriva da Gramática Funcional (GF) proposta por Dik (1997). Essa teoria, de acordo com Hengeveld e Mackenzie (2008), concebe o usuário da língua como conhecedor das regras formais e funcionais da linguagem e das formas de combinar essas regras.

A GDF é vista como um modelo de interação verbal cujo Componente Gramatical se une aos componentes Conceitual, Contextual e de Saída. Os três últimos componentes interagem com o Componente Gramatical por meio de operações de formulação (regras pragmáticas e semânticas de uma língua) e de codificação (regras que traduzem o morfológico, semântico e pragmático, e regras fonológicas).

O Componente Conceitual é responsável pelo desenvolvimento da interação comunicativa relevante para que seja produzido o ato de fala e os conceitos associados aos eventos extralinguísticos pertinentes. O Componente Contextual, por sua vez, contém uma descrição do conteúdo e da forma do discurso anterior e molda a forma na qual o ato de fala será produzido em função da relação social entre os participantes da conversação. O Componente de Saída gera sinais acústicos ou expressões de ortografia com base nas informações proporcionadas pelo Componente Gramatical. 
O Componente Gramatical se divide em quatro níveis de organização linguística: o Interpessoal (relacionado com a pragmática) e o Representacional (relacionado com a semântica) - responsáveis pelo processo de formulação - o Morfossintático (relacionado com a morfossintaxe) e o Fonológico (relacionado com a fonologia) encarregados pelo processo de codificação. Todos esses Níveis são impulsionados por um conjunto de primitivos e se organizam internamente em estratos hierárquicos.

O Nível Interpessoal, segundo Hengeveld e Mackenzie (2008), captura toda a formulação das distinções relativas à interação entre o falante e o ouvinte. A hierarquia presente dentro do Nível Interpessoal se organiza pelas camadas seguintes: Movimento (M), Ato Discursivo (A) e Conteúdo Comunicado (C). Esse Nível se refere aos aspectos pragmáticos da unidade da língua que refletem o papel da interação falante-ouvinte.

Esses papéis se analisam em termos de funções retóricas e pragmáticas. Dentre as Funções Retóricas encontram-se: Motivação, Orientação, Correção e Concessão. Como já mencionado, essas funções referem-se às formas em que os componentes do discurso são organizados pelo falante, a fim de alcançar seu propósito comunicativo, e também se relacionam às propriedades formais de um comunicado que influenciam o ouvinte a aceitar o que diz o falante. A concessão, portanto, para a GDF, é uma função retórica no Nível Interpessoal, isto é, é uma relação de dependência entre dois Atos Discursivos (A), um Nuclear (Ai) e outro Subsidiário (Aj), sendo que esse último deve ser entendido como uma estratégia de que dispõe o falante para alcançar seu objetivo comunicativo.

O Nível Representacional, por sua vez, se refere aos aspectos semânticos da unidade linguística. Enquanto o Nível Interpessoal evoca algo, o Nível Representacional é responsável pela designação. Por isso, a utilização do termo semântica se relaciona aos meios pelos quais uma língua lida com os mundos possíveis que ela descreve. As relações hierárquicas que são designadas neste Nível são: Conteúdo Proposicional (p), Episódios (ep), Estados-de-Coisas (e) e a Propriedade Configuracional (f).

O Nível Morfossintático, por sua vez, trata dos aspectos estruturais de uma unidade linguística. Juntamente com o Nível Fonológico, ele cuida da codificação das distinções interpessoais e representacionais. Diante dessa função, muito do que acontece no Nível Morfológico é funcionalmente motivado: princípios ordenadores são motivados por iconicidade, integridade de domínio e preservação das relações de escopo (HENGEVELD; MACKENZIE, 2008, p. 283). 
Já o Nível Fonológico, último Nível proposto pela teoria, é responsável pela parte da codificação que não foi abrangida pelo Nível Morfossintático. Esse Nível fornece um número de indicações, em cada camada, que o componente de saída converte em um resultado sonoro.

Como se observa, para a GDF, a concessão é uma função retórica, uma estratégia que o falante pode utilizar para atingir seus objetivos e guiar o ouvinte. Em pesquisa anterior (GARCIA; FANTE, 2015) investigamos os aspectos sintáticos, semânticos e pragmáticos de estruturas introduzidas por a pesar de (que) no espanhol falado a fim de determinar em que Nível e camada essas estruturas se constituem no escopo da GDF. Constatamos que a pesar sempre pede o preenchimento de um slot, que pode ser, no espanhol falado, uma frase nominal (construção sem verbo) ou uma oração. Por pedir um único complemento, a pesar configura, na Gramática DiscursivoFuncional, uma Propriedade Configuracional de um lugar $\left(\mathrm{f}_{1}\right)$ (HENGEVELD; MACKENZIE, 2008, p.139). Uma Propriedade Configuracional constitui o leque de esquemas de predicação relevante para uma determinada língua. Esse esquema de predicação pode variar de língua para língua. Para a GDF, as línguas diferem umas das outras em função do número e da natureza dos esquemas de predicação que são permitidos no que diz respeito à sua valência quantitativa.

Em Garcia e Fante (2015), foi possível observar que, em espanhol, o único slot requerido pela semântica de a pesar pode ser preenchido por uma oração desenvolvida, referindo-se à oração imediatamente anterior ou acrescentando uma informação a respeito de todo o contexto anterior, sempre na intenção de orientar o ouvinte, atuando, dessa forma, exclusivamente no Nível Interpessoal (pragmático). No primeiro caso, configura uma relação entre dois Atos Discursivos, quando constitui uma função retórica, conforme se observa na ocorrência (2) e, no segundo caso, configura um Movimento, uma oração que não se refere a uma oração principal, mas a todo o contexto anterior, servindo como um parêntese, algo que o falante julga necessário informar ao ouvinte, como pode ser visto na ocorrência (3).

(2) [...] Para la gran mayoría la muerte es oscura, fría, el paso a la nada, a pesar de que las creencias y las religiones busquen justificaciones y sacrificios en vida para un después tan eterno y maravilloso como aburrido. ${ }^{3}$ (CREA Oral, a vivir que son dos, Espanha, retransmissões esportivas).

(3) $[\ldots]$ Bueno, en principio, tú sabes que tenemos la oferta de abrigos de

3 [...] Para a grande maioria, a morte é obscura, fria, um passo para o nada, apesar de que as crenças e religiões busquem justificativas e sacrifícios durante a vida para um depois tão eterno e maravilhoso quanto chato. 
visón a trescientas noventa y cinco mil pesetas, que yo quiero mantener durante todo este mes de diciembre, a pesar de que puede que sea imposible, porque la el visón ha subido muchísimo de precio, pero voy a intentar mantener ese precio de tres-noventa y cinco. ${ }^{4}$ (CREA Oral, rádio, Espanha, variedades).

O slot também pode ser ocupado por uma oração reduzida de infinitivo ou por uma frase nominal (construção sem verbo), mas, nesses casos, essas estruturas não apresentam a função de guiar o interlocutor, mas sim a de representar um possível obstáculo para a realização do que o falante apresenta imediatamente a seguir, o que caracteriza tais construções no Nível Representacional da GDF. No primeiro caso, o das orações reduzidas, são estruturas localizáveis no tempo e no espaço, o que configura, na GDF, Estados-de-Coisas, como pode ser observado em (4); já no segundo caso, são estruturas que podem indicar Localização (l) e Tempo (t), as quais configuram, na GDF, subclasses de categorias, que entram na constituição de uma Propriedade Configuracional, conforme demonstra a ocorrência (5) abaixo:

(4) [...] hacía años que no participaba en este campeonato, y la verdad es que, $\boldsymbol{a}$ pesar de hacer unos obligatorios mediocres, hay que tener en cuenta también que era la segunda vez que los realizaba desde el campeonato del mundo de Stuttgart. ${ }^{5}$ (CREA Oral, retransmissiões esportivas, Espanha, retransmissões esportivas)

(5)[...] pero Alcalá es un pueblo// un pueblo culto/ un pueblo con: cultura// pero es un pueblo// o que pasa que a mí me gusta porque es grande// a pesar de pueblo pero luego es pueblo. ${ }^{6}(\mathrm{AH}, 03,15, \mathrm{H})$.

Dessa forma, em função da organização top down da GDF, a pesar é codificado, no Nível Morfossintático, como Conjunção, pois apresenta significado (pesar), assinalando a concessão. Assim, no processo de codificação morfossintática, é inserido a preposição $d e$, que codifica a função Referência (relação de dependência, de relação) no domínio morfossintático, quando também se insere a conjunção que nos casos de oração.

Os resultados mostram claramente que as estruturas introduzidas por a pesar de atuam no Nível Representacional e que as estruturas prefaciadas por a pesar de

$4[\ldots]$ Bom, a princípio, você sabe que temos a oferta de casacos de pele por 395 mil pesetas, que eu quero manter durante todo o mês de dezembro, a pesar de que pode ser que seja impossível porque o casaco de pele subiu muito de preço, mas vou tentar manter esse preço de três noventa e cinco.

5 [...] fazia anos que não participava deste campeonato e, a verdade é que, apesar de fazer uns obrigatórios medíocres, devemos levar em consideração também que era a segunda vez que os realizava desde o campeonato do mundo de Stuttgart.

6 [...] mas Alcalá é um povoado, um povoado culto, um povoado com cultura, mas é um povoado, o que acontece é que eu gosto porque é grande, apesar de povoado. 
que atuam no Nível Interpessoal, o que nos permite afirmar que, do ponto de vista da GDF, a pesar de e a pesar de que são conjunções diferentes, pois introduzem estruturas que atuam em diferentes Níveis e camadas.

Constatamos, portanto, que a pesar de que tende a atuar no Nível Interpessoal, nas camadas do Movimento ou do Ato Discursivo. Nesse caso, os verbos ocorrem predominantemente no indicativo, uma vez que das 24 ocorrências, $75 \%$ ocorrem no indicativo e apenas $25 \%$, no subjuntivo. Esse resultado confirma a hipótese de Crevels (1998) de que o uso do indicativo tende a ser recorrente nos estratos mais altos de organização linguística, tais como as Concessivas de Atos de fala ( $4^{\mathrm{a}}$ ordem) e as Concessivas Textuais ( $5^{\mathrm{a}}$ ordem). Confirmando o estatuto de Ato Discursivo e de Movimento de a pesar de que, observamos a presença de Atos Interativos nas fronteiras das orações concessivas pertencentes a essas camadas. Os Atos Interativos são estruturas voltadas para a interação e geralmente ocorrem no início ou no final dessas construções. Nos dados, pudemos observar muitos casos de orações seguidas pelos elementos pero, porque, pues, os quais não atuam como conjunção adversativa, causal ou explicativa, mas como elementos utilizados pelo falante para retomar o fio discursivo interrompido pela concessão quando ela ocorre como uma reconsideração ou como um parêntese, atuando no Nível Interpessoal.

Já as concessivas prefaciadas por a pesar de introduzem orações exclusivamente não-finitas, isto é, estruturas que ocorrem com verbo no infinitivo e estruturas desprovidas de núcleos verbais, ou seja, sintagmas nominais. Essas duas construções caracterizam, na GDF, respectivamente, Estados-de-Coisas e entidades como Tempo e Lugar, o que faz com que essa conjunção se constitua no Nível Representacional do modelo teórico adotado. Além disso, não foram detectados Atos Interativos nas fronteiras das orações concessivas, o que corrobora o estatuto de Estado-de-Coisas das orações introduzidas por essa conjunção.

A diferença de atuação da concessão, no Nível Interpessoal ou no Nível Representacional do modelo, representa grande influência na ordem. Os dados mostram que, quando a concessão atua no Nível Interpessoal, apresenta a função de persuadir o ouvinte e está voltada aos aspectos pragmáticos e interacionais. Em função disso, a estrutura concessiva tende a ocorrer após ou independentemente da oração principal. Já quando a concessão se dá no Nível Representacional, tende a funcionar como refutação de possíveis contra-argumentos do interlocutor (cf. NEVES, 1999), como algo que poderia interferir na oração principal, mas não 
interfere e, nesse caso, ocorre, geralmente, antes da oração principal. A ordem da oração concessiva com relação à principal, na visão da GDF, é um reflexo claro da integração entre os Níveis, isto é, representa o reflexo dos fatores interpessoais e representacionais sobre os fatores morfossintáticos.

Os fatores de análise utilizados na pesquisa anterior, como se pode observar, foram essenciais na distinção entre a pesar de e a pesar de que. Esses resultados, no entanto, nos instigaram a descrever essas duas conjunções de acordo com outros fatores de análise na busca por um que fosse crucial nessa distinção. Os novos fatores utilizados foram Factualidade, Pressuposição e Tempo de Referência, sobre os quais passamos a discorrer na seção (2) a seguir.

\section{Factualidade, Pressuposição e Tempo de Referência como fatores distintivos de a pesar de e a pesar de que}

Conforme postulam Zamproneo (1998), Neves (1999) e Flamenco García (1999), a subcategorização das orações concessivas em factuais, eventuais e contrafactuais é estabelecida com base nos tempos e modos verbais que a oração nuclear e a oração concessiva exibem. Tendo como base os postulados funcionalistas, podemos atribuir à Factualidade e à Pressuposição, dentre outros fatores, as diferenças nas relações modo-temporais. De acordo com a NGRAE (2009) a informação temporal e modal que está vinculada às orações concessivas é de certa complexidade, não somente pela variedade de esquemas modotemporais que são admitidos, mas também pela intersecção de valores semânticos que são expressos nessas correlações de tempo e modo. Dessa forma, nesta seção, analisaremos a questão da Factualidade, da Pressuposição e do Tempo de Referência verbal respectivamente em (2.1), (2.2) e (2.3).

\section{a. A Factualidade}

De acordo com Zamproneo (1998), Neves (1999), Flamenco García (1999) e NGRAE (2009), no que diz respeito à Factualidade, ou seja, à veracidade, as construções concessivas podem ser: factuais/reais, eventuais/potenciais/ hipotéticas/semifactuais ou contrafactuais/irreais ${ }^{7}$.

7 Para este artigo, adotaremos as denominações: factuais/ semifactuais e contrafactuais, conforme postula Flamenco García (1999). 


\section{a) Concessivas factuais}

Apesar da realização ou da verdade da oração concessiva, segue-se, necessariamente, a realização ou a verdade da oração principal. Na perspectiva de Neves (1999) e de Flamenco García (1999), neste caso, tanto a proposição da oração principal quanto a proposição da oração concessiva devem ser verdadeiras para que a asserção global seja também verdadeira. Isso significa que a enunciação de uma factual implica a realização dos conteúdos tanto da oração principal quanto da oração concessiva, conforme exemplifica (6):

(6) $[\ldots]$ dijimos vamos a la Moncloa y ya te tienen que ingresar/ pero por narices// tampoco la querían ingresar a pesar de que fue en ambulancia. ${ }^{8}(\mathrm{AH}$, 07, 31, H)

Podemos verificar em (6) que tanto o fato expresso pela oração concessiva (A pesar de que fue en ambulancia) quanto o fato expresso pela oração principal (tampoco la querían ingresar) são possíveis de se realizarem no mundo real e a sua concretização ou não concretização é de fácil verificação. Assim, podemos resumir tendo como base as palavras da NGRAE (2009), que no período real são expressos fatos tidos como verdadeiros ou esperáveis.

\section{b) Concessivas semifactuais}

No caso das concessivas semifactuais, Flamenco García (1999) e Neves (1999) afirmam que o conteúdo expresso por estas orações subordinadas pode ser interpretado como verdadeiro (com maior ou menor grau de probabilidade de ocorrência) ou como nem verdadeiro nem falso, sendo esta última interpretação a característica que distingue as concessivas semifactuais das concessivas factuais, em cuja definição se declara a certeza da verdade do conteúdo presente na oração subordinada.

Em termos gerais, podemos dizer que, dada a potencialidade da oração concessiva, não necessariamente se segue a realização ou a verdade, nem a não realização ou a falsidade, da oração principal. Isso significa que existe uma incerteza epistêmica sobre a eventual ocorrência do conteúdo proposicional da oração concessiva, como é notado na ocorrência (7):

$8[\ldots]$ dissemos vamos à Moncloa e já tem que te internar, mas por causa do nariz também não queriam interná-la, apesar de que foi em ambulância 
(7) (e:) se promocionará el aire acondicionado/ más que la calefacción///a pesar de que la calefacción pues puede ocurrir que (ts) que sea necesaria unos cuanto:s días/ al año. ${ }^{9}$ (AH, 15, 51, H)

Em (7), podemos observar que o conteúdo proposicional da oração principal é factual, verdadeiro (se promocionará el aire acondicionado/ más que la calefacción), mas o mesmo não ocorre necessariamente com o da concessiva, pois não se observa certeza no conteúdo expresso em (a pesar de que la calefacción pues puede ocurrir que sea necesaria unos cuantos días al año) já que, o verbo no subjuntivo sea, em espanhol, pode assinalar uma possibilidade, visto que a calefação pode ou não ser necessária.

\section{c) Concessivas contrafactuais}

No caso das concessivas contrafactuais ou irreais, segundo Neves (1999), tanto a oração principal quanto a oração concessiva devem ser não verdadeiras para que a asserção global seja também não-verdadeira. Isso significa que a enunciação de uma contrafactual implica a não realização dos conteúdos tanto da oração principal quanto da oração concessiva.

Segundo Flamenco García (1999, p. 3831), o conteúdo da oração concessiva é considerado falso, isto é, a ocorrência de tal fato é negada implicitamente nestes contextos. Assim, nessas construções, o falante sabe que o fato expresso na oração subordinada nem está sendo cumprido no presente, nem se cumpriu no passado, o que explica o uso do condicional simples (viviría) na oração concessiva em (8) a seguir:

A pesar de que de buena gana viviría en París, no se está tan mal aquí en Madrid. ${ }^{10}$ (FLAMENCO GARCÍA, 1999, p. 3832 - Adaptado)

Em (8), facilmente reconhecemos que o falante, na oração concessiva $A$ pesar de que de buena gana viviría en París, apresenta um fato irreal, improvável, que é morar em Paris. Desse mesmo modo, dizer que alguém está mal em Madri não é verdadeiro, o que leva o falante a afirmar o contrário de modo modalizado.

9 terá promoção de ar-condicionado mais do que de calefação, apesar de que a calefação pode ser necessária alguns dias do ano.

10 Apesar de que de boa vontade eu moraria em Paris, não se está tão mal aqui em Madri. 
Para Pérez Quintero (2002), a Factualidade é um parâmetro independente e aplicável a todos os tipos de entidades. Dessa forma, a autora considera como factuais as relações concessivas que descrevem: (i) propriedade ou relação como aplicável; (ii) estados-de-coisas como reais; (iii) conteúdos proposicionais como verdadeiros e (iv) Atos discursivos como assertivos.

Após a exposição da Factualidade como fator de análise da presente pesquisa, na seção (2.2) a seguir, discutiremos a definição de Pressuposição e sua relevância para este trabalho.

\section{b. A Pressuposição}

Na concepção de Neves (1999), nas construções concessivas está implícita a ideia de que existe uma hipótese, que é a hipótese de objeção por parte do interlocutor. Assim, no caso das construções concessivas, o falante:

A) registra na oração concessiva uma objeção que ele pressupõe que o ouvinte tenha;

B) deixa prevalecer, entretanto, a ideia expressa na oração principal.

Do mesmo modo, Neves et al (2008) declaram que ocorre na construção concessiva que o falante pressupõe a objeção do ouvinte (elemento hipotético), e declara que tal objeção não impedirá nem modificará o propósito expresso na oração nuclear (elemento opositivo).

Nessa perspectiva, concebemos, neste trabalho, a Pressuposição como um fator que se relaciona ao conhecimento do falante e do ouvinte, mais especificamente, à expectativa que o falante apresenta com relação ao conhecimento de seu ouvinte, algo entre os interlocutores da interação. Essa relação entre conhecimentos e pressuposições, na GDF, está concebida no Componente Contextual, que contém a descrição do conteúdo e da forma do discurso precedente, do contexto real perceptível em que ocorre o evento de fala e das relações sociais entre os participantes (HENGEVELD; MACKENZIE, 2012, p. 45).

Para determinar se uma relação é pressuposta ou não pressuposta, utilizamos os conceitos de tema e rema conforme a NGRAE (2009), que concebe tema como toda informação que é conhecida, podendo ser ou não ser explícita na interação. Em contrapartida, chamam-se rema as porções de enunciado consideradas novas, sendo importantes em uma situação discursiva para complementar uma informação que é temática. Cabe ressaltar aqui que quando o falante usa uma informação como nova, ele pressupõe que essa informação não é conhecida, isto é, o ouvinte 
não tem conhecimento sobre tal informação. Já quando o falante pressupõe que o interlocutor conhece a informação, trata-se de uma informação compartilhada pelos interlocutores ou, em outras palavras, informação dada.

Com base nesta definição, trabalhamos com a hipótese de que as orações factuais podem ser pressupostas ou não-pressupostas no sentido de que podem ser conhecidas ou não pelo ouvinte, enquanto as orações contrafactuais tendem a ser não pressupostas, isto é, tendem sempre a veicular uma informação nova, já que o falante apresenta uma hipótese ou uma possibilidade pela primeira vez ao seu interlocutor. É possível observar, portanto, que Pressuposição e Factualidade são conceitos intimamente atrelados.

A Pressuposição e a Factualidade se manifestam na materialidade linguística de várias formas, dentre as quais destacamos a escolha dos tempos e modos verbais pelos falantes.

Após a exposição dos conceitos de Pressuposição, a seguir, em (2.3), trataremos sobre o fator Tempo de Referência.

\section{c. O Tempo de Referência}

Para Leufkens (2013), tempo absoluto e tempo relativo são categorias gramaticais, e, portanto, segundo a Gramática Discursivo-Funcional (HENGEVELD; MACKENZIE, 2008), categorias modeladas como operadores. Nessa perspectiva, Tempo de Referência Absoluto é considerado uma propriedade do Episódio; enquanto Tempo de Referência Relativo é uma propriedade do Estado-de-Coisas. É importante deixar claro que o Episódio é uma unidade que inclui um ou mais Estados-de-Coisas. Um Estado-de-Coisas pode ser localizado no tempo - com relação a outro Estado-de-Coisas dentro do mesmo Episódio - por meio de operadores de tempo absoluto ou por meio de modificadores de tempo relativo.

A título de ilustração, com base em Leufkens (2013), vamos considerar tais propriedades na língua inglesa:

(9) Yesterday Sheila went out before dinner. ${ }^{11}$ (HENGEVELD; MACKENZIE, 2008, p. 171 apud LEUFKENS, 2013, p. 201).

No exemplo acima, segundo a autora, o modificador yesterday (um advérbio de tempo absoluto) localiza o Episódio no tempo, uma vez que Sheila's going out está localizado no passado. Before dinner (antes do jantar), que é um advérbio 
relativo frasal, localiza o primeiro Estado-de-Coisas going out (sair) com respeito a outro evento dinner (jantar). Já yesterday escopa before dinner, o que faz com que seja impossível inferir que o jantar ocorreu em outro dia que não seja yesterday (ontem).

Com base nisso, à luz da GDF, podemos dizer que um Episódio e seus Estadosde-Coisas estão localizados no tempo por significados de referência temporal absoluta, enquanto Estados-de-Coisas são localizados no tempo segundo outros Estados-de-Coisas.

É exatamente isso que pode ser visualizado em (10) abaixo, em que se observa que o Episódio todo se encontra no passado, caracterizando uma referência temporal absoluta, enquanto há dois Estados-de-Coisas que ocorrem simultaneamente, um contendo a forma não-finita was working, e ambos caracterizando uma referência temporal relativa:

(10) ...he felt very tired when he was working ${ }^{12}$.

(p1:

(past ep1:

[(sim e1: - he feel tired - (e1)) (sim e1: - he work - (e1))] (ep1))

(p1)) (DECLERCK'S, 1988, p. 512 apud LEUFKENS, 2013, p, 202)

Para Leufkens (2013), em oposição à oração principal, as orações subordinadas do inglês podem conter tempos relativos puros, isto é, nesses casos, nota-se que há certa dependência entre as orações, como é o caso de (11), em que está expressa uma relação de anterioridade, de (12), em que está expressa uma relação de simultaneidade, e de (13), em que está expressa uma relação de posterioridade:

(11) Having closed the door, he realized his keys were inside. ${ }^{13}$ (LEUFKENS, 2013, p. 202)

(12) He left sliding down a rope. ${ }^{14}$ (LEUFKENS, 2013, p. 203)

(13) He is the man to wash the dishes. ${ }^{15}$ (LEUFKENS, 2013, p. 203)

Os tempos relativos acima são todos expressos por formas não-finitas do predicado. Isso porque um tempo relativo puro não ativa um lexema especializado

12 Ele se sentiu muito cansado quando/enquanto estava trabalhando.

13 Tendo fechado a porta, ele percebeu que suas chaves estavam dentro.

14 Ele saiu escorregando pela corda.

15 Ele é homem para lavar a louça. 
ou afixo em inglês, mas sim é expresso por uma forma verbal que não veicula categorias gramaticais como tempo e aspecto. Dessa forma, a expressão associada em um operador de tempo absoluto e em um operador de tempo relativo (tanto na oração principal como na oração subordinada) leva à seleção de uma forma temporal auxiliar no Nível Morfossintático. Há nove combinações temporais possíveis, como pode ser visualizado na Tabela (1) a seguir, adaptada de Leufkens (2013, p. 203) para o espanhol:

TABELA 1: As nove possíveis combinações em espanhol para expressar operadores de tempo absoluto e de tempo relativo

\begin{tabular}{|c|c|c|c|}
\hline Tempo Absoluto & \multirow{2}{*}{ Passado } & \multirow{2}{*}{ Presente } & \multirow{2}{*}{ Futuro } \\
\hline Tempo Relativo & & & \\
\hline Anterior & $\begin{array}{l}\text { P r e t é r i t o } \\
\text { Pluscuamperfeito } \\
\text { habia cantado }\end{array}$ & $\begin{array}{l}\text { P r e t é r i t o } \\
\text { Perfeito } \\
\text { he cantado }\end{array}$ & $\begin{array}{l}\text { P r e t é r i t o } \\
\text { Pluscuamperfeito } \\
\text { do Subjuntivo } \\
\text { hubiera cantado } \\
\text { e Condicional } \\
\text { Composto } \\
\text { habría cantado }\end{array}$ \\
\hline Simultâneo & $\begin{array}{l}\mathrm{P} \text { r e } \mathrm{t} \text { é } \mathrm{r} \text { i t o } \\
\text { Indefinido } \\
\text { canté }\end{array}$ & $\begin{array}{l}\text { Presente } \\
\text { canto }\end{array}$ & $\begin{array}{l}\text { Futuro Simples } \\
\text { cantaré }\end{array}$ \\
\hline Posterior & $\begin{array}{l}\text { C o n d i c i o n a } 1 \\
\text { Simples } \\
\text { cantaría }\end{array}$ & - & $\begin{array}{l}\text { Futuro Perfeito } \\
\text { hubiere cantado }\end{array}$ \\
\hline
\end{tabular}

FONTE: Leufkens (2013) - adaptada para o espanhol.

$\mathrm{Na}$ Tabela (1), acima, podemos ver que os tempos de referência dependente (tempo relativo) e independente (tempo absoluto) podem estabelecer relações de anterioridade, simultaneidade e posterioridade no passado, no presente ou no futuro, de acordo com as nove combinações de tempos verbais possíveis.

De acordo com o que foi exposto acima, nota-se que a diferença entre uma oração que apresenta tempo absoluto e uma oração que apresenta tempo relativo consiste na possibilidade de que a primeira pode selecionar a referência temporal independentemente. Dessa forma, um tempo absoluto corresponde, nos termos de Hengeveld (1998), a uma referência temporal independente, enquanto um tempo 
relativo corresponde a uma referência temporal dependente. Essa relação pode ser feita porque o tempo absoluto, como já dito acima, se associa à escolha do tempo verbal - passado, presente ou futuro - que se estabelece independentemente de outro tempo verbal, enquanto o tempo relativo - simultâneo, posterior ou anterior - se associa às formas verbais não finitas, que, necessariamente, dependem de outro verbo para se constituírem.

Para Hengeveld (1998), o parâmetro de dependência temporal é relevante dentro de orações de $2^{\mathrm{a}}$ ordem (Estados-de-Coisas) apenas, pois as orações adverbiais de zero ordem necessariamente têm Tempo de Referência Independente, enquanto as de $3^{\mathrm{a}}$ e $4^{\mathrm{a}}$ ordem têm Tempo de Referência Dependente.

Após a exposição das considerações sobre Tempo de Referência do verbo, passaremos, a seguir, a discutir o que os dados coletados para a pesquisa aqui apresentada demonstraram, segundo os fatores Factualidade, Pressuposição e Tempo de Referência, discutidos nas seções anteriores.

\section{4. $O$ que os dados mostram}

Nesta seção, tratamos dos fatores de análise propostos para este trabalho Factualidade, Pressuposição e Tempo de Referência - aplicando-os às conjunções a pesar de e a pesar de que e tendo o tipo de camada na qual a concessão se estabelece como fator norteador para a análise dos resultados.

\section{a. A pesar de que}

No que diz respeito à Factualidade das orações concessivas prefaciadas por $a$ pesar de que, notamos que, das 24 ocorrências introduzidas por a pesar de que, $88 \%$ são factuais, enquanto apenas $12 \%$ são semifactuais. Não houve casos de orações contrafactuais. A Factualidade, fator que diz respeito à veracidade das orações, pôde ser detectada por meio do contexto da interação falante-ouvinte e por meio do tempo e do modo verbal das orações envolvidas na relação de concessão, conforme demonstram (14) e (15):

(14) $[\ldots]$ dijimos vamos a la Moncloa y ya te tienen que ingresar/ pero por narices// tampoco la querían ingresar a pesar de que fue en ambulancia. ${ }^{16}$ (AH, $07,31, \mathrm{H})$

16 [...] dissemos vamos à Moncloa e já tem que te internar, mas por causa do nariz também não queriam interná-la, apesar de que foi em ambulância. 
(15) (e:) se promocionará el aire acondicionado/ más que la calefacción/// a pesar de que la calefacción pues puede ocurrir que (ts) que sea necesaria unos cuanto:s dias/ al año. ${ }^{17}(\mathrm{AH}, 15,51, \mathrm{H})$

Em (14) nota-se que a oração principal está no Pretérito Imperfeito do Indicativo querían enquanto a oração subordinada veicula um verbo no Pretérito Indefinido do Indicativo fue. Considera-se, portanto, que a oração concessiva traz uma informação que é verdadeira, real e certa no passado; trata-se, na verdade, de um Ato Discursivo Assertivo, conforme Pérez Quintero (2002).

Por outro lado, nota-se em (15) que ambas as orações (principal e subordinada) veiculam um verbo que não designa que um fato real aconteceu ou está acontecendo, uma vez que a informação veiculada é de possível realização no futuro (pode ou não acontecer), pois na oração principal temos promocionará, no Futuro Simples, e na oração subordinada temos puede ocurrir, perífrase verbal de infinitivo que designa futuridade e incerteza, conforme a semântica do verbo poder que, neste caso, recebe uma leitura epistêmica. Em função dessa possibilidade (ou não) de ocorrência, consideramos as ocorrências como (15) casos de concessivas semifactuais. Embora reconheçamos a Assertividade do Ato Discursivo Nuclear (Ai) se promocionará el aire acondicionado más que la calefacción e a Assertividade do Ato Discursivo Subsidiário (Aj) a pesar de que la calefacción pues puede ocurrir que sea necesaria unos cuantos días al año, entendemos que (Ai) é real, enquanto (Aj) é potencial, ou seja, pode ocorrer ou não, o que configura um caso de concessiva semifactual.

É importante observar que os verbos utilizados em (14) e em (15) ocorrem no indicativo. Para Flamenco García (1999), com relação à expressão de conteúdos factuais, isto é, fatos constatados de realização efetiva, pode-se empregar tanto as formas do indicativo como as formas do subjuntivo. Segundo o autor, as concessivas factuais com indicativo assinalam um cumprimento efetivo de um fato, seja no presente, seja no passado, ou a convicção de um fato que está enfocado no futuro. Assim, nesses casos, a pesar de que pode introduzir todas as formas do indicativo em seus usos temporais, o que faz as orações adquirirem a seguinte relação interna com respeito aos usos do indicativo: a uma oração concessiva presente, em que se denota simultaneidade com o momento de fala, corresponderá uma oração principal com forma de posterioridade, de simultaneidade ou, mais

17 terá promoção de ar-condicionado mais do que de calefação, apesar de que a calefação pode ser necessária alguns dias do ano. 
raramente, de anterioridade.

A Tabela $(2)^{18}$ a seguir resume os resultados obtidos com relação à Factualidade das orações introduzidas por a pesar de que:

TABELA 2: Factualidade nas orações prefaciadas por a pesar de que

\begin{tabular}{|c|c|}
\hline & Apesar de que \\
\hline Factuais & $21-88 \%$ \\
\hline Semifactuais & $3-12 \%$ \\
\hline Contrafactuais & $0-0 \%$ \\
\hline
\end{tabular}

FONTE: elaboração das autoras.

Como é possível notar, a porcentagem de ocorrências semifactuais é bastante inferior à de orações concessivas factuais, o que demonstra que as orações concessivas introduzidas por a pesar de que tendem a veicular uma informação real, verdadeira.

No que diz respeito, por sua vez, à Pressuposição, detectamos que as orações concessivas prefaciadas por a pesar de que podem ser pressupostas e nãopressupostas, com tendência a serem não-pressupostas. Em (16), nota-se que na oração concessiva prefaciada por a pesar de que o falante introduz uma informação nova para o interlocutor, o que configura tal oração como não-pressuposta. Por outro lado, em (17), nota-se que o falante considera a oração concessiva como veiculadora de uma informação já conhecida pelo ouvinte, já mencionada anteriormente no discurso, o que configura tal oração como pressuposta:

(16) [...] la inmensa mayoría de los españoles se declaran como creyentes, aunque una parte significativa, también hay que decirlo, se declara como no practicante así pues, y a pesar de que los españoles conservan la fe, o por lo menos una cierta fe o una fe selectiva. ${ }^{19}$ (CREA Oral, debate, Espanha, religião)

(17) Los corredores han... durante estos últimos quilómetros han estado bajando muchos a los coches a pedir el casco el casco compacto, que les va muy

18 Para fins de padronização, todas as tabelas apresentadas na análise de dados indicam o número de ocorrências e a porcentagem correspondente a esse número.

19 [...] a imensa maioria dos espanhóis se declaram como crentes, ainda que uma parte significativa, deve-se mencionar, se declara como não-praticante, assim, pois, e apesar de que os espanhóis conservam a fé, ou ao menos uma certa fé, ou uma fé seletiva. 
bien de cara al sprint porque el circuito de la Castellana, pues bueno, siempre tiene su peligro. Y, bueno, aprovecho para decir que, a pesar de que muchos no lo lleven, es bueno siempre para los chavales. ${ }^{20}$ (CREA Oral, vuelta ciclista, Espanha, retransmissões esportivas)

Os dados mostram que há correspondência entre o tipo de camada dentro da Gramática Discursivo-Funcional em que se enquadra a oração concessiva e a questão da Pressuposição. Pudemos observar que 10 ocorrências, ou $41 \%$ das orações prefaciadas por a pesar de que analisadas, pertencem à camada do Ato Discursivo, enquanto 14 ocorrências, ou $59 \%$ das orações, se enquadram na camada do Movimento, ambas camadas do Nível Interpessoal. A análise revela que as orações concessivas pertencentes à camada do Movimento apresentam tendência a serem não pressupostas (57\%), enquanto as orações concessivas pertencentes à camada do Ato Discursivo apresentam tendência a serem pressupostas $(60 \%)$, o que pode ser explicado quando olhamos para a natureza das concessivas, pois as de Movimento geralmente introduzem uma informação nova, que o falante julga importante e necessária no momento da interação, enquanto as que atuam na camada do Ato Discursivo, como função retórica, servem para guiar e para orientar o ouvinte, o que não faz dessa uma informação nova necessariamente. Com respeito a isso, a Tabela (3) abaixo ilustra as porcentagens encontradas:

TABELA 3: Correspondência entre a Pressuposição da oração e a camada de acordo com a GDF

\begin{tabular}{|l|c|c|}
\hline \multicolumn{3}{|c|}{ A pesar de que } \\
\hline & Tipo de camada a que pertence à oração concessiva \\
\hline & Movimento & Ato Discursivo \\
\hline Pressupostas & $4-43 \%$ & $8-60 \%$ \\
\hline Não-pressupostas & $6-57 \%$ & $6-40 \%$ \\
\hline
\end{tabular}

Fonte: elaboração das autoras.

20 Os corredores, durante esses últimos quilômetros, têm parado muito os carros, pedindo o capacete, o capacete compacto, que vai muito bem para eles de cara ao sprint porque o circuito de Castellana, pois, bem, sempre tem seu perigo. E, bom, aproveito para dizer que, apesar de que muitos não o levam, é bom sempre para os garotos. 
Como se pode observar, os números mostram que tanto as concessivas que atuam na camada do Movimento como as que atuam na camada do Ato Discursivo apresentam apenas uma pequena tendência a serem não-pressupostas e pressupostas respectivamente. Assim, a Tabela (3) nos permite dizer que o fator Pressuposição ajuda, mas não é determinante na distinção entre $a$ pesar de e $a$ pesar de que. O fator crucial, no entanto, parece ser o Tempo de Referência, sobre o qual passaremos a discorrer.

A análise do Tempo de Referência das estruturas envolvidas mostra que tal fator não se aplica nos casos em que a oração concessiva corresponde à camada do Movimento, uma vez que, em tais casos, a oração concessiva não faz referência a uma oração principal, mas, sim, a toda porção discursiva enunciada anteriormente. Dessa forma, detectamos que, nas orações concessivas prefaciadas por a pesar de que pertencentes à camada do Ato Discursivo, o Tempo de Referência da oração concessiva é sempre independente, ou seja, trata-se de orações cujo tempo é absoluto, pois a concessiva ocorre com verbo no passado, presente ou futuro que se estabelece independentemente do tempo verbal presente na oração principal. É o que podemos notar em (18) a seguir:

(18) $\quad$ E: $<$ simultáneo $>$ cuesta arran $<$ palabra_cortada $/><$ vacilación $/><$ / simultáneo $>$ salir de $<$ alargamiento/ $>$ / de la ciudad

I: sí cuesta/l a pesar de que yo creo que tiene considerables ventajas ${ }^{21}$ (M, 33, H23, AH)

Em (18) nota-se que há uma relação de simultaneidade no presente entre as orações principal, cujo verbo está no Presente do Indicativo cuesta, e subordinada, cujo verbo também está no Presente do Indicativo creo. Apesar disso, os verbos se constituem, nas duas orações, independentemente, uma vez que não há a presença de formas verbais dependentes, como é o caso do infinitivo, do particípio ou do gerúndio.

Com isso, podemos resumir os dados analisados referentes aos fatores Factualidade, Pressuposição e Tempo de Referência em associação com o Nível e com a camada correspondente na Gramática Discursivo-Funcional de acordo com a Tabela (4):

I: Sim, custa, apesar de que eu acredito que tem vantagens consideráveis. 
Orações concessivas prefaciadas por a pesar de e a pesar de que no espanhol peninsular falado: factualidade, pressuposição e tempo de referência à luz do funcionalismo

TABELA 4: Resultados quantitativos sobre a pesar de que

\begin{tabular}{|l|l|l|l|l|l|l|l|l|}
\hline \multicolumn{8}{|c|}{ Resultados das análises de a pesar de que } \\
\hline & \multicolumn{2}{|c|}{$\begin{array}{c}\text { Camada de } \\
\text { atuação na GDF }\end{array}$} & \multicolumn{2}{|c|}{ Factualidade } & \multicolumn{2}{c|}{ Pressuposição } & \multicolumn{2}{c|}{$\begin{array}{c}\text { Tempo de } \\
\text { Referência }\end{array}$} \\
\cline { 2 - 9 } & $\begin{array}{l}\text { Movi- } \\
\text { mento }\end{array}$ & $\begin{array}{l}\text { Ato } \\
\text { Discur- } \\
\text { sivo }\end{array}$ & Factual & Potencial & Pressup. & $\begin{array}{l}\text { Não- } \\
\text { pressup. }\end{array}$ & Dep. & Indep. \\
\cline { 2 - 9 } $\begin{array}{l}\text { pesar } \\
\text { de } \\
\text { que }\end{array}$ & $14-$ & $\begin{array}{l}10- \\
58 \%\end{array}$ & $\begin{array}{l}42 \% \\
88 \%\end{array}$ & $3-12 \%$ & $\begin{array}{l}13- \\
54 \%\end{array}$ & $11-46 \%$ & $\begin{array}{l}0- \\
0 \%\end{array}$ & $\begin{array}{l}24- \\
100 \%\end{array}$ \\
\hline
\end{tabular}

FONTE: elaboração das autoras.

A seguir, em (3.2) apresentaremos nossas conclusões com relação à análise de a pesar de.

\section{b. A pesar de}

Com relação ao primeiro fator proposto para esta análise, a Factualidade, é preciso enfatizar que foi aplicável somente aos casos oracionais de a pesar de, pois os casos não oracionais não permitem a aplicação desse critério.

Como foi mencionado na seção (2.1) deste artigo, para Neves (1999), no caso das orações concessivas factuais, tanto a proposição da oração principal, quanto a proposição da oração concessiva, devem ser verdadeiras para que a asserção global da ocorrência seja também verdadeira. É o que podemos notar na ocorrência (19) a seguir em que a conjunção a pesar de introduz uma oração não-finita pertencente à camada do Estado-de-coisas, no Nível Representacional, sendo, nos termos de Pérez Quintero (2002), um Estado-de-Coisas real, pois tener todo de sobra constitui uma entidade como real:

(19) [...] hoy veo yo que no hay tanta felicidad// no/ a pesar de tener todo y de sobra// no hay tanta felicidad como hemos tenido nosotros en nuestros tiempos. ${ }^{22}$ (G, 34, M32, M)

A Factualidade nas orações concessivas introduzidas por a pesar de reduzidas de infinitivo foi um fator unânime, isto é, todas as orações não finitas encontradas

22 [...] hoje vejo eu que não há tanta felicidade, não, apesar de ter tudo e de sobra, não há tanta felicidade como a que tivemos em nosso tempo. 
no corpus (11 ocorrências), veiculam uma informação verdadeira, ou seja, Estadosde-Coisas reais. Isso porque, uma oração concessiva introduzida por a pesar de contrafactual seria agramatical, como pode ser visto na paráfrase de (19’) a seguir, em que se observa um contexto totalmente improvável:

(19') [...] *yo he sido feliz/ siempre///"/ hoy veo yo que no hay tanta felicidad// no/ a pesar de hubiera tenido/habría tenido/tenía y de sobra ${ }^{23} / /$ no hay tanta felicidad

Nos casos de orações introduzidas por a pesar de em que não se verifica a presença de formas verbais, ou seja, são casos de sintagmas nominais (16 ocorrências), o fator Factualidade não foi aplicado, uma vez que, para esta pesquisa, nos baseamos nos efeitos de realidade, verdade e assertividade da entidade a partir dos efeitos de sentido e das formas verbais como pistas sinalizadoras. A partir disso, a Tabela (5) apresenta resumidamente a presença desse fator nas orações analisadas:

TABELA 5: Factualidade nas orações prefaciadas por a pesar de

\begin{tabular}{|l|c|c|}
\hline & A pesar de + infinitivo & A pesar de + sintagmas \\
\hline Factuais & $11-100 \%$ & - \\
\hline Semifactuais & $0-0 \%$ & - \\
\hline Contrafactuais & $0-0 \%$ & - \\
\hline
\end{tabular}

Fonte: elaboração das autoras.

Com relação à Pressuposição, pudemos observar que a tendência das orações introduzidas por a pesar de é a de registrar a informação veiculada pela oração subordinada como pressuposta, isto é, o falante considera que a informação registrada já é conhecida pelo interlocutor e, além disso, a informação também é tomada por esse mesmo falante como de real realização, isto é, factível. $\mathrm{Na}$ GDF, isso é facilmente compreendido quando nos atentamos para o que significa o Componente Contextual, já que esse componente corresponde à descrição do conteúdo e da forma discursiva no contexto real perceptível em que a interação e

23 [...] hoje vejo eu que não há tanta felicidade, não, apesar de tivesse tido/ havia tido/tinha tudo e de sobra, não há tanta felicidade. 
as relações sociais entre os interlocutores ocorrem

Hengeveld (1998) afirma que a Pressuposição está atrelada à questão da Factualidade, o que equivale a dizer que esse fator diz respeito à pressuposição do falante de tomar determinado evento como real ou verdadeiro.

A análise mostra que não há correspondência entre a Pressuposição e a posição da oração concessiva com respeito à oração principal, uma vez que, independentemente de a oração concessiva ser pressuposta ou não-pressuposta, tais orações podem ser posteriores ou anteriores à oração principal. As ocorrências (20) e (21) ilustram a questão da Pressuposição com relação à ordenação da oração concessiva.

(20) $[. .$.$] pero mañana pero mañana mañana volveremos con nuestro abogado$ de barrio aquí, a pesar de ser el día de nochebuena[...]. ${ }^{24}$ (CREA Oral, radio, Espanha, variedades)

(21) [...] hay partes tan mágicas como la vida nocturna encerrados en casa, como el paseo, como los sueños, como la magia nocturna, lo de las estrellas, la luna, y la mitología nocturna, y la fauna nocturna. a pesar de los medios técnicos, a pesar de la modernidad que caracteriza a comediants..$^{25}$ (CREA Oral, un día es un día, Espanha, magacines)

Notamos que em (20) acima, o fragmento em análise veicula uma informação que, além de pressuposta como verdadeira (factual), é também pressuposta pelo falante como conhecida do ouvinte por meio de seu conhecimento de mundo, pois ele sabe que no Natal normalmente não se trabalha, o que dificultaria a presença de um advogado no local. Por outro lado, notamos que em (21) as informações prefaciadas por a pesar de são não-pressupostas pelo falante como conhecidas do ouvinte, uma vez que o falante introduz tais informações como forma de argumentar a seu favor, isto é, defender seu ponto de vista. Além disso, consideramos importante destacar como o falante faz uma cadeia de orações concessivas com a pesar de, o que notamos ser possível apenas nos casos em que essa conjunção introduz sintagmas.

Considerando que o fator Pressuposição se aplica tanto às orações com infinitivo, como às orações com sintagmas, a Tabela (6) ilustra a presença deste

24 [...] mas amanhã voltaremos aqui com nosso advogado de bairro, apesar de ser dia de Natal. 25 [...] há coisas tão mágicas, como a sucinta vida noturna em casa, como o passeio, como os sonhos, como a magia noturna, as estrelas, a lua, a mitologia noturna, a fauna noturna, apesar dos meios técnicos e apesar da modernidade que caracteriza os comediantes. 
fator nas orações analisadas:

TABELA 6: Pressuposição nas orações prefaciadas por a pesar de

\begin{tabular}{|l|c|c|}
\hline & $\begin{array}{l}\text { A pesar de }+ \text { infinitivo (11 } \\
\text { ocorrências })\end{array}$ & $\begin{array}{l}\text { A pesar de }+ \text { sintagmas } \\
(16 \text { ocorrências })\end{array}$ \\
\hline Pressupostas & $9-81 \%$ & $13-81 \%$ \\
\hline Não-pressupostas & $2-19 \%$ & $3-19 \%$ \\
\hline
\end{tabular}

FONTE: elaboração das autoras.

É perceptível, na Tabela (6), que as orações pressupostas são maioria no tipo de oração em análise, sendo que as orações não-pressupostas ocorreram em número bastante reduzido, o que revela a tendência das estruturas introduzidas por a pesar de serem pressupostas.

No que diz respeito ao terceiro fator de análise, Tempo de Referência, mais uma vez tal classificação não se aplica aos casos de orações que veiculam sintagmas. Isso porque o Tempo de Referência Absoluto, como já apresentado na seção (2.3), corresponde, nos termos de Hengeveld (1998), a uma referência temporal independente, enquanto um tempo relativo corresponde a uma referência temporal dependente. Essa relação pode ser feita porque o tempo absoluto se associa à escolha do tempo verbal - passado, presente ou futuro - que se estabelece independentemente de outro tempo verbal, enquanto o tempo relativo - simultâneo, posterior ou anterior - se associa às formas verbais não finitas, que, necessariamente, dependem de outro verbo para se constituírem.

A partir disso, notamos que no caso das orações concessivas prefaciadas pelo nexo a pesar de, os tempos são expressos pela forma não finita do verbo, sempre no infinitivo, o que significa que o uso do verbo não tem correspondência com os elementos intrínsecos às formas verbais absolutas, como tempo, aspecto, número e pessoa. Isso significa, portanto, que as formas verbais não finitas correspondem a tempos de referência relativos, ou, nos termos de Hengeveld (1998), a tempos de referência dependentes, uma vez que as relações que são estabelecidas com verbo da oração subordinada (relações de anterioridade, posterioridade ou simultaneidade) dependem do verbo da oração principal. 
Além disso, é importante ressaltar que, para Hengeveld (1998, p.348), as relações de dependência temporal acontecem necessariamente dentro de Estadosde-Coisas (e), o que vai ao encontro dos resultados obtidos neste estudo. A ocorrência (22) a seguir pode ilustrar tais relações estabelecidas:

(22) [...] lo que pasa que mi hermano mayor es/ lo he idealizado un poco/y yo cuando/ como nunca estaba// cuando venía/ a mí siempre me/ lo que más me gustaba era estar con él// y me/ y jugaba mucho con él/ porque a pesar de ser// casi doce o trece años mayor que yo. ${ }^{26}(\mathrm{G}, 27, \mathrm{H} 22, \mathrm{M})$

Em (22) notamos que o verbo da oração principal y jugaba mucho con él/ porque, jugaba, corresponde ao tempo verbal Pretérito Imperfeito do Indicativo em espanhol, enquanto na oração subordinada prefaciada por a pesar de o verbo está na forma não-finita ser (infinitivo), estabelecendo uma relação de dependência entre os Estados-de-Coisas em uma relação representada pela simultaneidade no passado.

Assim, a partir de tudo o que foi exposto sobre as análises se a pesar de, podemos sintetizar, na Tabela (7), as conclusões a que esta pesquisa nos levou, considerando os fatores Factualidade, Pressuposição e Tempo de Referência para as orações introduzidas por a pesar de:

Tabela 7: Análise geral de a pesar de

\begin{tabular}{|c|c|c|c|c|c|c|c|c|}
\hline & \multicolumn{2}{|c|}{$\begin{array}{l}\text { Posição } \\
\text { da Oração } \\
\text { Subordinada }\end{array}$} & \multicolumn{2}{|c|}{ Factualidade } & \multicolumn{2}{|c|}{ Pressuposição } & \multicolumn{2}{|c|}{$\begin{array}{l}\text { Tempo de } \\
\text { Referência }\end{array}$} \\
\hline & $\begin{array}{l}\text { Ante- } \\
\text { posta }\end{array}$ & $\begin{array}{l}\text { Pos- } \\
\text { posta }\end{array}$ & $\begin{array}{l}\text { Fac- } \\
\text { tual }\end{array}$ & $\begin{array}{l}\text { Semi } \\
\text { ou } \\
\text { Contra } \\
\text { factual }\end{array}$ & Pressup. & $\begin{array}{l}\text { Não- } \\
\text { Pres- } \\
\text { suposta }\end{array}$ & Depend. & $\begin{array}{l}\text { Inde- } \\
\text { pend. }\end{array}$ \\
\hline $\begin{array}{l}\text { A pesar } \\
\mathrm{de}+ \\
\text { infinitivo }\end{array}$ & $\begin{array}{l}6- \\
55 \%\end{array}$ & $\begin{array}{l}5- \\
45 \%\end{array}$ & $\begin{array}{l}11- \\
100 \%\end{array}$ & $0-0 \%$ & $10-91 \%$ & $1-9 \%$ & $\begin{array}{l}11- \\
100 \%\end{array}$ & $0-0 \%$ \\
\hline $\begin{array}{l}\text { A pesar } \\
\text { de }+ \\
\text { sintagmas } \\
\end{array}$ & $\begin{array}{l}8- \\
50 \%\end{array}$ & $\begin{array}{l}8- \\
50 \%\end{array}$ & - & - & $13-81 \%$ & $3-19 \%$ & - & - \\
\hline
\end{tabular}

Fonte: elaboração das autoras.

26 [...] o que acontece com meu irmão mais velho é que, eu o idealizei um pouco, e eu quando/ como nunca estava quando ele vinha, sempre me, o que eu mais gostava era estar com ele, e brincava muito com ele, apesar de ser quase doze ou treze anos mais velho do que eu. 


\section{Considerações Finais}

Os dados mostram que tanto as orações prefaciadas por a pesar de quanto as orações prefaciadas por a pesar de que tendem a veicular uma informação real, podendo ser um Estado-de-Coisas real ou Atos e Movimentos Assertivos. A análise revela que a pesar de (que) tem a tendência de veicular informações reais e verdadeiras, nunca hipotéticas ou irreais.

Já no que diz respeito à Pressuposição, detectamos que ambas as orações, sejam introduzidas por a pesar de sejam prefaciadas por a pesar de que, veiculam informações pressupostas pelo ouvinte como verdadeiras, ou informações já conhecidas pelo ouvinte porque já foram mencionadas anteriormente ou foram determinadas contextualmente. Assim, a hipótese com a qual trabalhamos - de que as orações factuais tendem a ser pressupostas ou não pressupostas enquanto as orações contrafactuais tendem a ser não pressupostas, isto é, tendem sempre a veicular uma informação nova - foi confirmada para os casos de $a$ pesar de e $a$ pesar de que, pois a concessão prefaciada pelas duas conjunções em análise tende a ser factual, pressuposta ou não pressuposta, sendo que as orações pressupostas foram mais recorrentes. Além disso, é importante mencionar que Pressuposição e Factualidade são conceitos intimamente atrelados um ao outro, tendo em vista que são critérios semântico-pragmáticos e a materialização se dá, dentre outros fatores, nos tempos e modos verbais no domínio morfossintático. Esses dois fatores, não entanto, podem ser analisados somente em termos de tendência, pois o fator crucial para a análise foi o Tempo de Referência.

Pudemos observar que esse critério é determinante para assinalar as distinções entre a pesar de e apesar de que. O primeiro caso, a pesar de, apresenta Tempo de Referência Dependente já a pesar de que apresenta Tempo de Referência Independente, conforme Hengeveld (1998). Os tempos dependentes são todos expressos por formas não finitas do predicado, isto é, por uma forma verbal que não veicula categorias gramaticais como tempo e aspecto. Enquanto isso, os tempos independentes são expressos por relações de passado, presente ou futuro de forma independente, ou seja, sem dependência entre as orações principal e subordinada. Podemos dizer, portanto, que a diferença entre orações que apresentam Tempo de Referência Absoluto e Tempo de Referência Relativo consiste na possibilidade de selecionar a referência temporal independentemente.

Para concluir e sintetizar os resultados obtidos da presente análise do espanhol 
Orações concessivas prefaciadas por a pesar de e a pesar de que no espanhol peninsular falado: factualidade, pressuposição e tempo de referência à luz do funcionalismo

falado referente às concessivas prefaciadas por a pesar de e por a pesar de que, apresentamos a Tabela (8):

TABELA 8: Informações gerais sobre as análises de a pesar de e a pesar de que

\begin{tabular}{|l|l|l|l|l|l|l|}
\hline & \multicolumn{2}{|l|}{ Factualidade } & \multicolumn{2}{l|}{ Pressuposição } & \multicolumn{2}{l|}{$\begin{array}{l}\text { Tempo de } \\
\text { Referência }\end{array}$} \\
\hline & Factual & $\begin{array}{l}\text { Semi ou } \\
\text { Contra } \\
\text { factual }\end{array}$ & Pressup. & $\begin{array}{l}\text { Não- } \\
\text { pressup. }\end{array}$ & Dep. & Indep. \\
\hline $\begin{array}{l}\text { A pesar de } \\
\text { (infinitivo) }\end{array}$ & $11-$ & $0-0 \%$ & $10-91 \%$ & $\begin{array}{l}1- \\
9 \%\end{array}$ & $\begin{array}{l}11- \\
100 \%\end{array}$ & $0-0 \%$ \\
\hline $\begin{array}{l}\text { A pesar de } \\
\text { (sintagmas) }\end{array}$ & - & $-00 \%$ & $13-81 \%$ & $3-19 \%$ & - & - \\
\hline $\begin{array}{l}\text { A pesar de } \\
\text { que }\end{array}$ & $\begin{array}{l}21- \\
87,5 \%\end{array}$ & $\begin{array}{l}3- \\
12,5 \%\end{array}$ & $13-54 \%$ & $11-46 \%$ & $0-$ & $\begin{array}{l}24 \% \\
0 \%\end{array}$ \\
\hline
\end{tabular}

FONTE: elaboração das autoras.

A Tabela (9) a seguir contempla todos os fatores utilizados na análise das ocorrências introduzidas por a pesar de e a pesar de que, pois aborda tanto os fatores utilizados em pesquisa anterior (cf. GARCIA; FANTE, 2015) quanto os fatores utilizados no presente trabalho:

TABELA 9: Análise geral de a pesar de e a pesar de que

\begin{tabular}{|c|c|c|}
\hline Conjunção & A pesar de & A pesar de que \\
\hline $\begin{array}{c}\text { Tipo (FLAMENCO } \\
\text { GARCÍA, 1999) }\end{array}$ & Locução prepositiva & Locução conjuntiva \\
\hline Nível em que atua & NR & NI \\
\hline
\end{tabular}




\begin{tabular}{|c|c|c|}
\hline Camada em que atua & $\begin{array}{c}\text { Estado-de-Coisas, } \\
\text { Subcategoria } \\
(\mathrm{t}, \mathrm{l})\end{array}$ & $\begin{array}{c}\text { Movimentos } \\
\text { Atos Discursivos }\end{array}$ \\
\hline Função & Função semântica concessão & $\begin{array}{c}\text { Função retórica } \\
\text { concessão }\end{array}$ \\
\hline Verbos & Infinitivo & $\begin{array}{c}\text { Subjuntivo/ } \\
\text { Indicativo }\end{array}$ \\
\hline $\begin{array}{c}\text { Identidade entre os } \\
\text { participantes }\end{array}$ & Geralmente sim & Sim/Não \\
\hline $\begin{array}{c}\text { Presença de Atos } \\
\text { Interativos nas fronteiras }\end{array}$ & Não & Sim \\
\hline Acidente prosódico & Sim & Pressupostas \\
\hline Pressuposição & Pressupostas & Factuais \\
\hline Factualidade & Factuais & Independentes \\
\hline Tempo de Referência & Dependentes & \\
\hline
\end{tabular}

Assim, concluímos que a pesar de e a pesar de que são, de fato, conjunções diferentes, já que, à luz da Gramática Discursivo-Funcional, constituem-se em Níveis e camadas distintos, apresentando o Tempo de Referência como principal fator norteador desta distinção.

\section{Oraciones concesivas introducidas por 'a pesar de' e 'a pesar de que' en el español peninsular hablado: Factualidad, Presuposición y Tiempo de Referencia a la luz del funcionalismo}

\section{RESUMEN}

Esta investigación objetiva describir, bajo la teoría de la Gramática Discursivo-Funcional, las oraciones concesivas introducidas por a pesar de (que) en español peninsular hablado, con el propósito de verificar en qué medida los criterios Factualidad, Presuposición y Tiempo de Referencia pueden distinguir a pesar de y a pesar de que y cómo esos criterios pueden 
ser reconocidos en la materialidad lingüística de esas construcciones, teniendo en cuenta que a pesar de y a pesar de que introducen estructuras de naturalezas distintas, siendo, respectivamente, frases nominales y oraciones. El universo de investigación consiste en el corpus del PRESEEA (Proyecto para el Estudio Sociolingüistico del Español de España y de América) y en el corpus del proyecto CREA (Corpus de Referencia del español actual). Los resultados enseñan que las oraciones introducidas por a pesar de suelen presentar una información factual y presupuesta, mientras las oraciones introducidas por a pesar de que suelen presentar una información también factual, pero presupuesta o no presupuesta. El análisis revela que el criterio determinante para distinguir las dos conjunciones es el Tiempo de Referencia, pues a pesar de presenta Tiempo de Referencia Dependiente, mientras que a pesar de que presenta Tiempo de Referencia Independiente.

Palabras-clave: Gramática Discursivo-Funcional. Concesión. Español hablado. A pesar de. A pesar de que.

\section{Referências}

CREVELS, Mily. Concession in Spanish. In: HANNAY, Mike; BOLKESTEIN, A. Machtelt. Functional Grammar and verbal interaction. Amsterdam/ Philadelphia: John Benjamin Publishing Company, v. 44, 1998. p. 129-148.

DIK, Simon. The theory of Functional Grammar. HENGEVELD, Kees. (Ed.). Berlin, New York: Mouton de Gruyter, 1997.

FLAMENCO GARCÍA, Luis. Las construcciones y adversativas. In: BOSQUE, Ignacio; DEMONTE, Violeta. Gramática Descriptiva de la Lengua Española. v.3. Madrid: Espasa, 1999.

GARCIA, Talita Storti; FANTE, Bárbara Ribeiro. Las estructuras concesivas introducidas por 'a pesar de (que)' en el español hablado desde la perspectiva Discursivo-Funcional. Signo y Seña - Revista del Instituto de Lingüística. v.27, p.223-245, 2015.

HENGEVELD, Kees. Adverbial Clauses in the languages of Europe. In: AUWERA, J. Adverbial Constructions in the languages of Europe. Berlim, New York: Mouton de Gruyter, 1998, p. 335-419.

HENGEVELD, Kees; MACKENZIE, J. Lachlan. Functional Discourse Grammar: a typologically-based theory of language structure. Oxford: University Press, 2008.

HENGEVELD, Kees; MACKENZIE, J. Gramática Discursivo-Funcional. In: 
SOUZA, E.R. (Org.) Funcionalismo linguístico: novas tendências teóricas. São Paulo: Contexto, 2012. p. 43-85.

KEIZER, Evelien. A functional discourse grammar for English. United Kingdom: Oxford University Press, 2015.

LEUFKENS, Sterre. Time reference in English indirect speech. In: MACKENZIE, J. L; OLBERTZ, H. ed. Casebook in Functional Discourse Grammar. Amsterdan: Benjamins, 2013, p. 189-212.

MATTE BON, Francisco. Gramática Comunicativa del Español. Madrid: Edelsa, tomo II, 1995.

NEVES, Maria Helena de Moura. As construções concessivas. In: NEVES, Maria Helena de Moura. (Org.). Gramática do português falado. São Paulo: Humanitas / FFLCH/USP; Campinas: Editora da UNICAMP, v. 7: Novos estudos, 1999. p. 545-591.

NEVES, Maria Helena de Moura; BRAGA, Maria Luiza; DALL'AGLIO HATTNHER, Marize Mattos. As construções hipotáticas. In: ILARI, Rodolfo; NEVES, Maria Helena de Moura. Gramática do português culto falado no Brasil. Campinas: Editora da UNICAMP, v. 2: Classes de palavras e processos de construção, 2008. p. 937-1015.

PÉREZ QUINTERO, María Jesús. Adverbial subordination in English: a functionalist approach. Amsterdam: Rodopi, 2002.

PRESEEA. Corpus del Proyecto para el estudio sociolingüístico del español de España y de América. Alcalá de Henares: Universidad de Alcalá. Disponível em: $<$ http://preseea.linguas.net $>$ (acesso em jan.2014).

REAL ACADEMIA ESPAÑOLA Y ASOCIACIÓN DE ACADEMIAS DE LA LENGUA ESPAÑOLA. Nueva Gramática de La Lengua Española. v 3. Madrid: Espasa Libros, 2009.

REAL ACADEMIA ESPAÑOLA: Banco de datos (CREA) [en línea]. Corpus de referencia del español actual. Disponível em $<$ http://www.rae.es $>$ (acesso em jul. 2015).

REAL ACADEMIA ESPAÑOLA. Gramática de la Lengua Española. Madrid: Espasa-Calpe, 1991.

ZAMPRONEO, Silvana. A Hipotaxe Adverbial Concessiva no Português Escrito Contemporâneo do Brasil. Tese de doutorado, Universidade Estadual Paulista "Júlio de Mesquita Filho", Campus de Araraquara, 1998.

Submetido: 28/03/2016

Aceite: 06/09/2016 